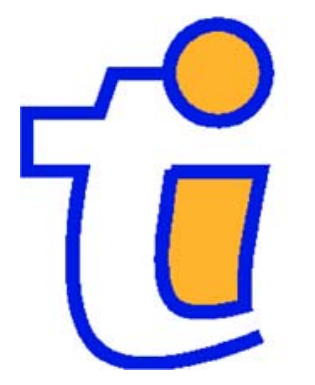

TI 2004-099/1

Tinbergen Institute Discussion Paper

Reciprocity and Emotions: Arousal, Self-Reports, and Expectations

Gershon Ben-Shakharl

Gary Bornstein'

Astrid Hopfensitz ${ }^{2}$

Frans van Winden²

' Department of Psychology, Hebrew University of Jerusalem;

2 Faculty of Economics and Econometrics, Universiteit van Amsterdam, and Tinbergen Institute. 
Tinbergen Institute

The Tinbergen Institute is the institute for economic research of the Erasmus Universiteit Rotterdam, Universiteit van Amsterdam, and Vrije Universiteit Amsterdam.

Tinbergen Institute Amsterdam

Roetersstraat 31

1018 WB Amsterdam

The Netherlands

Tel.: $\quad+31(0) 205513500$

Fax: $\quad+31(0) 205513555$

Tinbergen Institute Rotterdam

Burg. Oudlaan 50

3062 PA Amsterdam

The Netherlands

Tel.: $\quad+31(0) 104088900$

Fax: $\quad+31(0) 104089031$

Please send questions and/or remarks of nonscientific nature to driessen@tinbergen.nl.

Most TI discussion papers can be downloaded at http://www.tinbergen.nl. 


\title{
RECIPROCITY AND EMOTIONS: Arousal, Self-Reports, AND EXPECTATIONS
}

\author{
Gershon Ben-Shakhar ${ }^{1}$, Gary Bornstein ${ }^{2}$ \\ Astrid Hopfensitz ${ }^{3}$, Frans van Winden ${ }^{4 *}$
}

This version: September 2004

${ }^{1},{ }^{2}$ Department of Psychology, Hebrew University of Jerusalem, Jerusalem 91905, Israel ${ }^{3},{ }^{4}$ CREED, University of Amsterdam, 1018 WB Amsterdam, The Netherlands

* Corresponding author; E-mail: F.A.A.M.vanWinden@uva.nl

\begin{abstract}
Although reciprocity is a key concept in the social sciences, it is still unclear why people engage in costly reciprocation. In this study, physiological and self-report measures were employed to investigate the role of emotions, using the Power-to-Take Game. In this 2-person game, player 1 can claim any part of player 2's resources, and player 2 can react by destroying some (or all) of these resources thus preventing their transfer to player 1. Both physiological and self-report measures were related to destruction decisions and expectations. The pattern of emotional arousal and its correlation with self-reported anger highlights the importance of using both techniques for studying reciprocity.
\end{abstract}

JEL Classification: A12, C72, C91

Keywords: emotions, bargaining, laboratory experiment, expectations, reciprocity, physiological arousal, self-report measures of emotions

Acknowledgements: We are very thankful to Ori Cohen, Avia Munchik and Alona D. Roded for their excellent research assistance. Further we want to thank Ronald Bosman, Samuel Bowles and participants at conferences at the Santa Fe Institute, the ESA meeting in Amsterdam and the ISRE meeting in New York for helpful comments. Financial support by the European Union through the TMR research network ENDEAR (FMX-CT98-0238) and by the Israel Science Foundation (grant 907/01) is gratefully acknowledged. 


\section{Introduction}

Challenged by many observations that cannot be explained by the standard model of perfectly rational Homo economicus, behavioral economists are now trying to incorporate robust psychological findings into their models. This particularly holds for cognitive factors (Rabin, 1998; Camerer, 2003), but there is also a growing interest in the role of emotions in economic behavior (Elster, 1998; Loewenstein, 2000). A fascinating concurrent development is the use of neuroimaging techniques, with neuroeconomics emerging as a new field (Camerer et al., 2003). Notwithstanding that this is a promising new development, for social sciences like economics, these techniques have a drawback because they are difficult and costly to use for investigating social decision-making in groups or markets. This is illustrated by a recent study applying functional neuroimaging to the Ultimatum Game. Although it has been noted that deception should be avoided in experimental economics (Davis and Holt, 1993), the authors had to resort to deception (faking the presence of the second player) because of the heavy logistic demands (Sanfey et al., 2003). Therefore, it seems important to explore complementary techniques that are more practical for investigating decision-making in social interaction. Focusing on emotions, physiological and self-report measures are the main candidates. These more conventional measures have been validated and are relatively well understood by psychologists and are thus very valuable. This study applies both, physiological measures and self-reports, to investigate the emotional basis of reciprocity in bargaining, using the Power-to-Take Game (Bosman and van Winden, 2002).

In the two-person Power-to-Take Game, which is played only once and anonymously, both players receive equal endowments. One player (the take authority) has to decide first on how much money to take from the other player (the responder), that is, the take rate. 
Subsequently, after observing this take rate, responders have the option of destroying any percentage (from $0 \%$ to $100 \%$ ) of their own money. The money that is left after this destruction, together with the take rate, determines how much the take authority appropriates and what remains for the responder. Note that, for take rates greater than zero, the take authority will always end up with greater earnings than the responder. Consequently the Power-to-Take Game is a stark setting for reciprocity, a simple but realistic representation of many forms of social interaction involving appropriation ${ }^{1}$.

Standard economic theory predicts that responders will never destroy anything if the take rate is less than $100 \%$ because any destruction would leave them with less money, and more money is assumed to be preferable to less. However, substantial punishment through destruction has been observed in experiments ${ }^{2}$. Moreover, destruction has been found to be strongly correlated with the experienced intensity of anger-type emotions as reported by responders (Bosman and van Winden, 2002). This result is in line with the suggestion of the above-mentioned neuroimaging study of the Ultimatum Game, that emotional brain systems play an important role in the rejection of money offers ${ }^{3}$. Interestingly, in Power-to-Take Game experiments, emotional intensity has also been found to be related to the difference between the actual and the expected take rate, in line with the psychological observation that unexpectedness and disappointment are important triggers of emotions (Frijda, 1986; Ortony et al., 1988). In this study we used a physiological measure (skin conductance level) correlated with emotional arousal to shed more light on the relationships between destruction, expectations, and experienced emotions (Win-

\footnotetext{
${ }^{1}$ For further discussion and applications, see (Bosman and van Winden, 2002).

${ }^{2}$ Many other observations of costly punishment in economic games exist (Camerer, 2003; Fehr and Gaechter, 2002).

${ }^{3}$ The Power-to-Take Game differs from the Ultimatum Game (Gueth et al., 1982) in three respects. First, both players have their own endowment (instead of one endowment provided to both). Second, only the endowment of one player (the responder) is at stake. Third, responders can destroy any part of their endowment (not just everything or nothing).
} 
ton et al., 1984). In addition, self-reports were used to investigate the correspondence between the physiological and behavioral measures. Because of the ease and low costs of using self-reports, and because of the information they can provide on the types of emotions involved, a clear correspondence between the two measures would be important for stimulating research on the role of emotions in interactive behavior. In this respect, our work is also relevant to the study of emotions more generally. Moreover, self-reports seem to be the only way to get (direct) access to the expectations of subjects.

\section{Design and Procedures}

The game we are using is a simplified version of the Power-to-Take Game (Bosman and van Winden, 2002). In this game one of the players - the 'take authority' - is endowed with an initial income $Y_{\text {take }}$ and the other player - the 'responder' - with an initial income $Y_{\text {resp }}$ (in the experiment, $Y_{\text {take }}=Y_{\text {resp }}$ ). The game is played once and consists of two stages. In the first, the randomly chosen 'take authority' decides on a take rate $t$ of either 20 or 80 percent of the responder's money $Y_{\text {resp }}$, which will be transferred to the take authority ${ }^{4}$. In the second stage, after being informed of the take rate $t$, the responder has to decide on a destruction rate $d$, which is the percentage of $Y_{\text {resp }}$ that the responder destroys. After the destruction decision, the percentage $t$ claimed by the take authority is transferred. Thus for the take authority the total payoff of the game is $Y_{\text {take }}+t(1-d) Y_{\text {resp }}$. For the responder, the total payoff equals $(1-t)(1-d) Y_{\text {resp }}$.

In this game the responder can only destroy his or her own initial income $\left(Y_{\text {resp }}\right)$ and not the initial income of the take authority $\left(Y_{\text {take }}\right)$. Therefore the responder will earn at most $0.8 \cdot Y_{\text {resp }}$, while the take authority gets at least $Y_{\text {take }}$.

\footnotetext{
${ }^{4}$ In the game by Bosman and van Winden, the take rate could be chosen continuously out of the range $[0,100]$. Due to restrictions imposed by the physiological measurements, only a few data points could be collected per session and therefore the take authority's decision was restricted to a binary choice.
} 
Our experiment combined two methods of measuring emotions. First, as in Bosman and van Winden (Bosman and van Winden, 2002), we measured emotions after the second stage of the game, when responders have taken their destruction decisions, by offering them a (paper and pencil) questionnaire with a list of emotion names (fear, jealousy, anger, sorrow, happiness, shame, rage, contempt, joy, surprise and frustration). Subjects were asked to indicate on a 7-point scale the intensity of each emotion as felt when they were informed about the take rate (with 1 on the scale representing 'the emotion was not present at all', and 7 representing 'the emotion was strongly present'). The second method was based on a measure of emotional arousal of the responder during the experiment. Specifically, skin conductance level (SCL) was continuously monitored throughout the experiment. SCL reflects emotional arousal and can therefore be used as a measure of emotional reaction to the take authority's decision. SCL is usually not controlled by the subject and in this respect can be considered more reliable and objective than self-reports. In contrast with self-reports, however, it cannot provide specific information about the content of the experienced emotions because it only measures the level of arousal. In our experiment, each session consisted of two pairs of subjects, that is, four players, one of which (a responder) was connected to the $\mathrm{SC}$-device ${ }^{5}$.

The experiment was conducted in the Laboratory of Cognitive Psychophysiology, at the Hebrew University of Jerusalem. Subjects were recruited via advertisements promising monetary reward and academic credit. In total, 99 sessions were conducted with four subjects participating in each session. Subjects were seated in four separate rooms, each of which was equipped with a computer, writing utensils, blank paper and a calculator. All computers were networked with a central master computer in the experimenter's office.

\footnotetext{
${ }^{5}$ Technical problems in some cases made it impossible to collect SC data. Furthermore, in some of the many sessions not all participants showed up, which made it necessary to use stand-ins. These subjects were never involved in the pairs from which the responder's SC was measured. To exclude any potential influence of advance knowledge, the data of these subjects were not considered in the analysis.
} 
Upon entrance, each of the four subjects chose an envelope containing a 10 NIS (approximately $\$ 2.25)$ show-up fee and a number that assigned the subject to one of four separate rooms. Each subject was given written instructions, which indicated that 100 points would be allotted to each subject as initial income, with each point being equivalent to 0.5 NIS (see the Appendix for an English translation of the instructions). In addition, each room's door was left slightly open, and the experimenter read the instructions aloud while standing in the central hallway of the lab. Subsequently, the experimenter entered each room to answer questions and check a short quiz the subjects were asked to fill out.

Then one of the four subjects (always in the role of responder) was connected to the electrodes and given an explanation regarding the electrodermal measurement. The SCL was continuously monitored throughout the experiment by the master computer ${ }^{6}$. Following a two-minute rest period, the 'start' page of the experiment appeared on all the subjects' computer screens and the experiment began (Fig. 1).

At the first stage of the game, the computer screen offered each take authority the option to claim either $20 \%$ or $80 \%$ of the responder's income in points. Each responder was immediately informed of their respective counterpart's decision. In the analysis this point in time was labeled take.

Sixty-five seconds after take, responders were given the opportunity to destroy any percentage of their own income (on a scale ranging from $0 \%$ to $100 \%$ ) by typing the appropriate number on the keyboard. In the analysis the moment when the participant clicked on the percentage to be destroyed was labeled destruct.

During the 65 seconds following take, a timer appeared on the screen counting down the seconds, so that participants were well aware of the time they had to wait before being

\footnotetext{
${ }^{6}$ Skin conductance was measured by a constant voltage system (0.5 V Atlas Researches) and two $\mathrm{Ag} / \mathrm{AgCl}$ electrodes (0.8 cm diameter) were used with a $0.05 \mathrm{M} \mathrm{NaCl}$ electrolyte (Ben-Shakhar and Gati, 2003).
} 
able to make their destruction decision.

Following the 65 seconds after destruct, all four players were presented with a screen informing them how much money (in points) they were left with.

At the end of the experiment, each of the two subjects in the role of responder was asked to fill out an emotion questionnaire. All subjects filled out an anonymous biographical data questionnaire. Then an experimenter entered each room separately and handed the subject an envelope containing his or her earnings (average experimental earnings were 47.20 NIS ${ }^{7}$ ). Subjects received a short oral debriefing from the experimenter and were asked to maintain confidentiality regarding the experiment.

In total, 358 subjects participated in the experiment, mostly undergraduate students at the Hebrew University (average age of 23 years). Of the participants $37 \%$ were male and $63 \%$ female; while $24 \%$ were students of either business or economics, the others came from a variety of fields.

\section{Results}

Behavioral results regarding take rates and the percentage of responders who destroyed something, replicated earlier findings, except that the mean destruction rate was somewhat lower ${ }^{8}$ (Fig. 2). The take rate of 80 (20) was chosen $64.4 \%$ (35.5\%) of the time, rendering a mean take rate of 58.6 percent. The mean destruction rates were $4.89 \%$ and $15.15 \%$ for take rates of 20 and 80 , respectively, and overall $27.3 \%$ of the responders destroyed something.

Differences in destruction rates between SC and non-SC responders were small and not statistically significant (Mann-Whitney, $p>0.79$ ). Similarly, no statistically significant

\footnotetext{
${ }^{7}$ The total average payment of 57 NIS (including the show-up fee) equaled approximately $\$ 13$.

${ }^{8}$ This may be due to the imposed binary choice of the take authority (Falk et al., 2003).
} 
differences in self-reported emotions were found between these two groups, suggesting that the application of the SC-device as such did not influence behavior. Therefore, from now on we will focus on the results only for responders connected to the SC-device ${ }^{9}$.

We started our analysis using the following two variables as physiological measures: $S C L_{\text {take }}$, representing the maximum skin conductance level during the five-second interval after take, and $S C L_{\text {increase }}$, which stands for the difference between the skin conductance level measured at 65 seconds after take and $S C L_{\text {take }} . S C L_{\text {increase }}$ shows the change in arousal level of the responder in the one-minute waiting period before the destruction decision had to be typed in on the computer. First, we compared the average SCL values, taken during the two-minute rest period before the start of the game, of responders who destroyed money with those who did not (Fig. 3), and found that the two groups had very similar levels of SCL during rest. However, once the take rate had been announced, a strikingly different pattern of physiological response emerged for these two groups. Initially, as indicated by $S C L_{\text {take }}$, a somewhat higher level was observed for subjects who did not destroy anything - which is also the case if we consider only subjects who faced a take rate of 80 - but these differences were not statistically significant (Mann-Whitney, $p>$ 0.685). Following this initial increase, non-destroyers showed a continuously decreasing arousal level over the one-minute waiting period before they had to make their destruction decision, until it almost returned to the rest period base-rate. In sharp contrast, the arousal level of destroyers monotonically increased during the very same period. The difference between these two SCL patterns, which was measured by $S C L_{\text {increase }}$, was statistically significant (Mann-Whitney, $p=0.005$ ). This qualitative difference in arousal pattern may be explained by a difference in the timing of the mental decision to destroy

\footnotetext{
${ }^{9}$ These results are not qualitatively affected by the exclusion of the few subjects who reported that parts of the experiment were unclear or for whom the SC level deviated significantly from that of the others.
} 
something. We suggest that whereas non-destroyers make their decision early on (based on cognitive analysis), destroyers delay their destruction decision and make it sometime during the waiting period. The decrease in SCL of non-destroyers during the waiting period reflects the fact that they had already made up their mind at that point. On the other hand, the increase in arousal level observed for destroyers during the waiting period reflects the conflict they experienced between the (cognitive) interest to earn as much money as possible and the (emotional) urge to punish the take authority. It has been noted that such conflicts are associated with high arousal (Greene et al., 2001; Sanfey et al., 2003).

Once the game had ended, the difference in electrodermal level between destroyers and non-destroyers disappeared again. At first, both groups showed an increased SCL after their formal and irrevocable destruction decision, but then their SCL decreased (with destroyers staying at a slightly higher level). At the end of the one-minute waiting period following this decision, non-destroyers had once again returned to their baseline SCL.

Turning to the self-reported emotions, we first note that the mean score on the 7point scale for any given emotion never exceeded 3. Also, the variances of the intensity scores were smaller than in previous findings ${ }^{10}$. Therefore the emotion scores were split into high and low values (with the median as the cutoff point). Consistent with earlier findings, destroyers reported significantly more anger than non-destroyers (Pearson chisquare, $p=0.045)$. For other emotions no statistically significant differences were found. However, anger, rage, and contempt produced significant intercorrelations $(p=0.001)$.

Our results, which are consistent with previous findings, suggest that destruction is related to negative emotions and frustrated expectations (when the actual take rate is higher than the expected take rate). Responders were asked after the game, which take

\footnotetext{
${ }^{10}$ Again, this may be due to the restricted choice for the take authorities, but it may also be related to cultural differences (Manstead and Fischer, 2002).
} 
rate they had expected ${ }^{11}$, and subjects who expected a take rate lower than the actual take rate reported significantly more anger and rage (Fig. 4(a) $)^{12}$. In addition, subjects whose expectations were not confirmed were significantly more surprised than subjects who had their expectations confirmed (Pearson chi-square, $p<0.001$ ). Furthermore, destruction turned out to be significantly related to the actual take rate being higher than the expected take rate (Pearson chi-square, $p=0.039$ ) (Fig. 4(b)).

Having found that both the physiological and the self-reported emotion measures were associated with destruction, we examined the relationship between the two types of measures. Interestingly, the intuitive hypothesis that negative emotions should be associated with high arousal immediately after observing the take rate was not confirmed. However, this hypothesis overlooks the fact that arousal can result from being pleasantly surprised when observing a lower than expected take rate ${ }^{13}$. Finally, the experienced anger was related to $S C L_{\text {increase }}$. Specifically, subjects experiencing higher levels of anger also showed higher levels of $S C L_{\text {increase }}$ (Mann-Whitney, $p=0.064 ; p=0.029$ if restricted to a take rate of 80$)$.

\section{Conclusions}

This study investigated the role of emotions in the seemingly irrational decision to destroy one's own resources in the one-shot Power-to-Take Game. Physiological measures of emotional arousal as well as self-report measures of emotional responses were employed. Since appropriation and reciprocity are social phenomena of major importance for all

\footnotetext{
${ }^{11}$ Expected and actual take rates were not significantly correlated (Pearson chi-square, $p=0.540$ ).

${ }^{12}$ Since not all subjects replied that they had an expectation of either $20 \%$ or $80 \%$, our dataset for these observations is smaller.

${ }^{13}$ In the neuroimaging study of the Ultimatum Game referred to above (Sanfey et al., 2003), which showed neural evidence of negative emotions playing a role in the rejection of money, this potential effect was not addressed. However, because the authors did not allow responders to be confronted with offers smaller than $50 \%$, it may not have played an important role in their study.
} 
behavioral scientists, a better understanding of the role emotions play in reciprocative behavior should be of wide concern. Both of the measurement methods we used provided evidence for the role of emotions as well as frustrated expectations in the decision to punish through destruction. Moreover, the correlations between self-report measures of emotions and the physiological measures provide further justification for the use of self-reports in the study of reciprocity. 


\section{Appendix}

\section{Written Instructions (translation)}

Welcome, this is an experiment in decision making. During the experiment, you will be asked to make decisions and so will the other participants. Your choice as well as the other participants' choices, will determine the sum of money you receive, according to the rules which will be explained shortly. The money will be paid to you in cash at the end of the experiment exactly according to the rules. You are asked to remain seated quietly during the experiment. If you have questions, please wait in your room and an experimenter will enter and answer them.

Four people are participating in the experiment (you and 3 others). The participants will be divided randomly into 2 pairs. Each participant in each pair will have an initial sum of 100 points (with every point worth half a NIS), that is, a 50 NIS sum for each participant.

In each pair, one player will be randomly assigned to be player $\mathrm{A}$ and the other player will be assigned to be player B. Player B can take a certain percentage of player A's money. Player B should decide whether to take $20 \%$ or $80 \%$ of player A's money. Player B cannot choose not to take any of player A's money, nor can he/she take all of player A's money. After player A is notified via the computer about player B's choice, player A can decide to destroy any percentage he/she chooses of his/her own money.

For example, if player B chooses to take $80 \%$ of player A's money, and player A decides to destroy $50 \%$ of his/her points, then player B would get 40 points of player A's money (in addition to the initial 100 points he/she was given at the beginning of the experiment), and player A would be left with 10 points.

Another example: if player B chooses to take $20 \%$ of player A's money, and player A 
decides to destroy all of his/her points, then player B would not get any of player A's money and would have only the initial 100 points, and player A would be left with no points.

Note: the game will be played only once, and there is only one decision to be made, so please consider your decision carefully.

After the experiment, participants will be given feedback about the overall sum of points they gained and these points will be converted into money, at the rate of one point $=0.5$ NIS.

[A short quiz with 4 examples of possible decision scenarios was included. To make sure that the subjects understood the rules, each subject had to calculate the number of points each player would end up with.] 


\section{References}

Ben-Shakhar, G. and Gati, I. (2003). The effects of serial position and frequency of presentation of common stimulus features on orienting response reinstatement. Psychophysiology, 40:139-145.

Bosman, R. and van Winden, F. (2002). Emotional Hazard in a Power to Take Experiment. The Economic Journal, 112:147-169.

Camerer, C. (2003). Behavioral Game Theory. Princeton University Press.

Camerer, C. F., Loewenstein, G., and Prelec, D. (2003). Neuroeconomics: How Neuroscience can inform economics. mimeo.

Davis, D. and Holt, C. (1993). Experimental Economics. Princeton University Press.

Elster, J. (1998). Emotions and Economic Theory. Journal of Economic Literature, XXXVI:47-74.

Falk, A., Fehr, E., and Fischbacher, U. (2003). On the Nature of Fair Behavior. Economic Inquiry, 41(1):20-26.

Fehr, E. and Gaechter, S. (2002). Altruistic punishment in humans. Nature, 415:137-140.

Frijda, N. (1986). The Emotions. Cambridge University Press.

Greene, J. D., Sommerville, R. B., Nystrom, L. E., Darley, J. M., and Cohen, J. D. (2001). An fMRI Investigation of Emotional Engagement in Moral Judgment. Science, 293:2105-2108. 
Gueth, W., Schmittberger, R., and Schwarze, B. (1982). An experimental analysis of ultimatum bargaining. Journal of Economic Behavior and Organization, 3(4):367388.

Loewenstein, G. (2000). Emotions in Economic Theory and Economic Behavior. AEA Papers and Proceedings, 90(2).

Manstead, A. and Fischer, A., editors (2002). Culture and Emotions. Psychology Press.

Ortony, A., Clore, G., and Collins, A. (1988). The Cognitive Structure of Emotions. Cambridge University Press.

Rabin, M. (1998). Psychology and Economics. Journal of Economic Literature, 36:11-46.

Sanfey, A., Rilling, J., Aronson, J., Nystrom, L., and Cohen, J. (2003). The Neural Basis of Economic Decision making in the Ultimatum Game. Science, 300:1755-1758.

Winton, W. M., Putnam, L. E., and Krauss, R. M. (1984). Facial and Autonomic Manifestations of the Dimensional Structure of Emotion. Journal of Experimental Social Psychology, 20:195-216. 


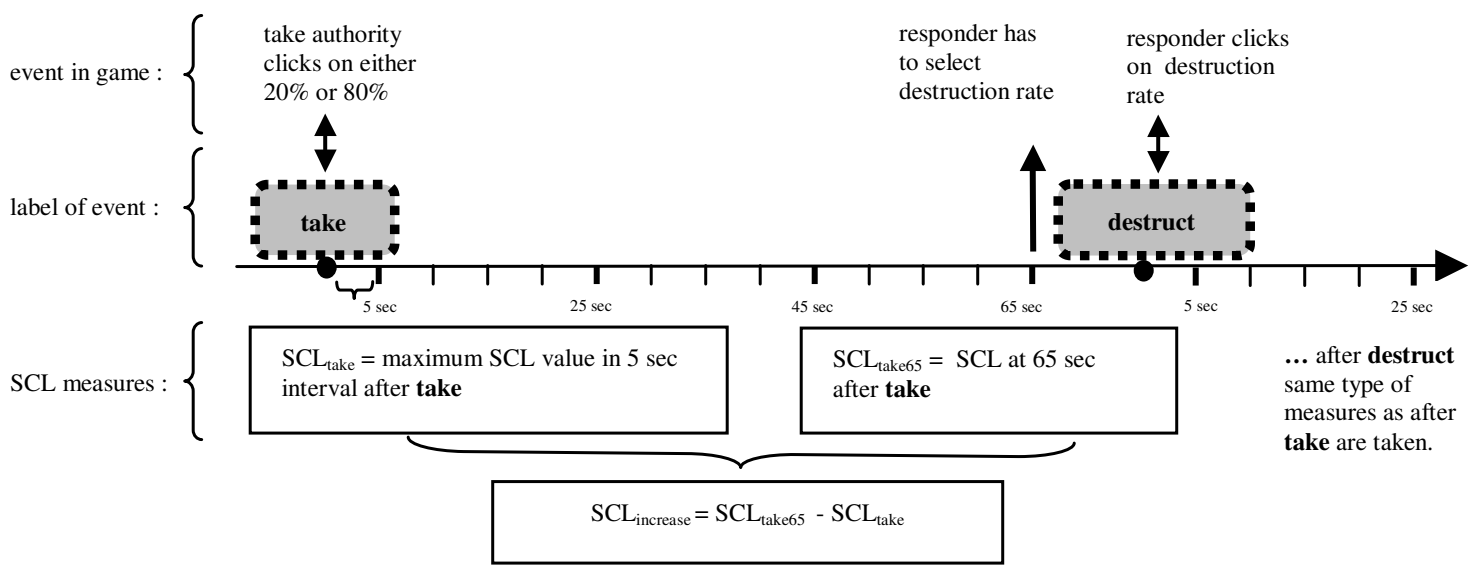

Figure 1: Order of SCL measures in the experiment. After the take and destroy event, respectively, four SCL measures were taken: the maximum SCL in the 5 sec. following the event and the SCL at 25, 45 and 65 sec. following the event.

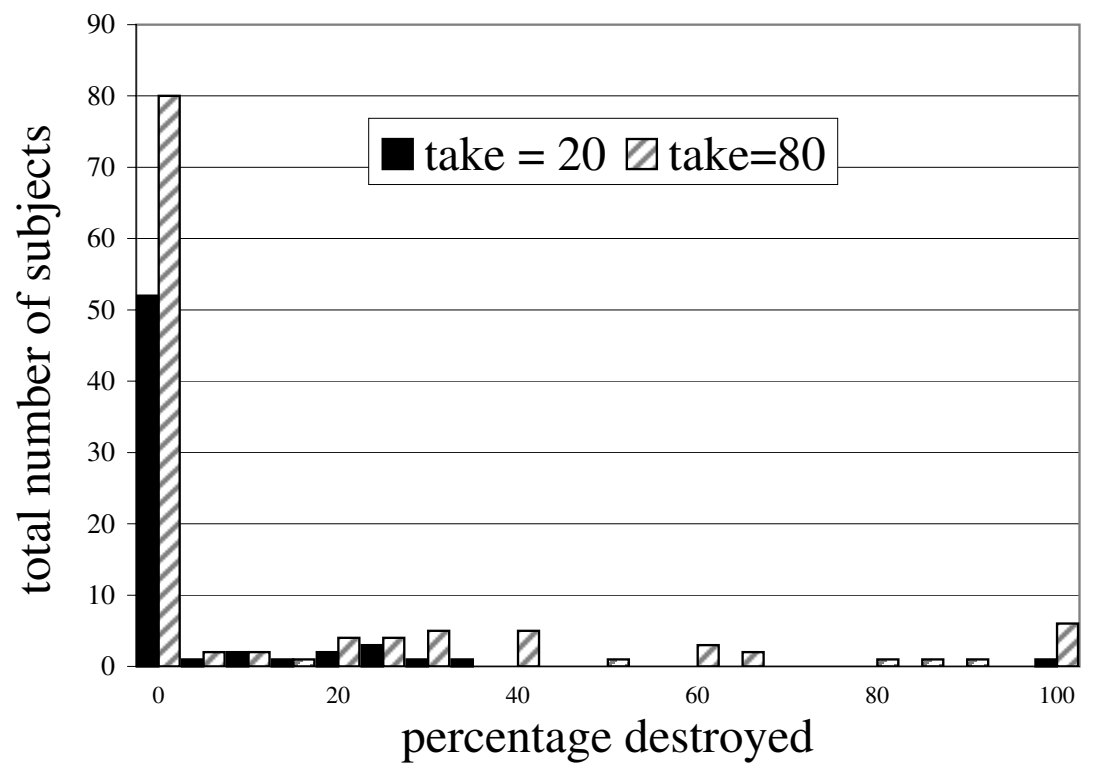

Figure 2: Histogram of the destruction rates for all responders - split over take rates. 


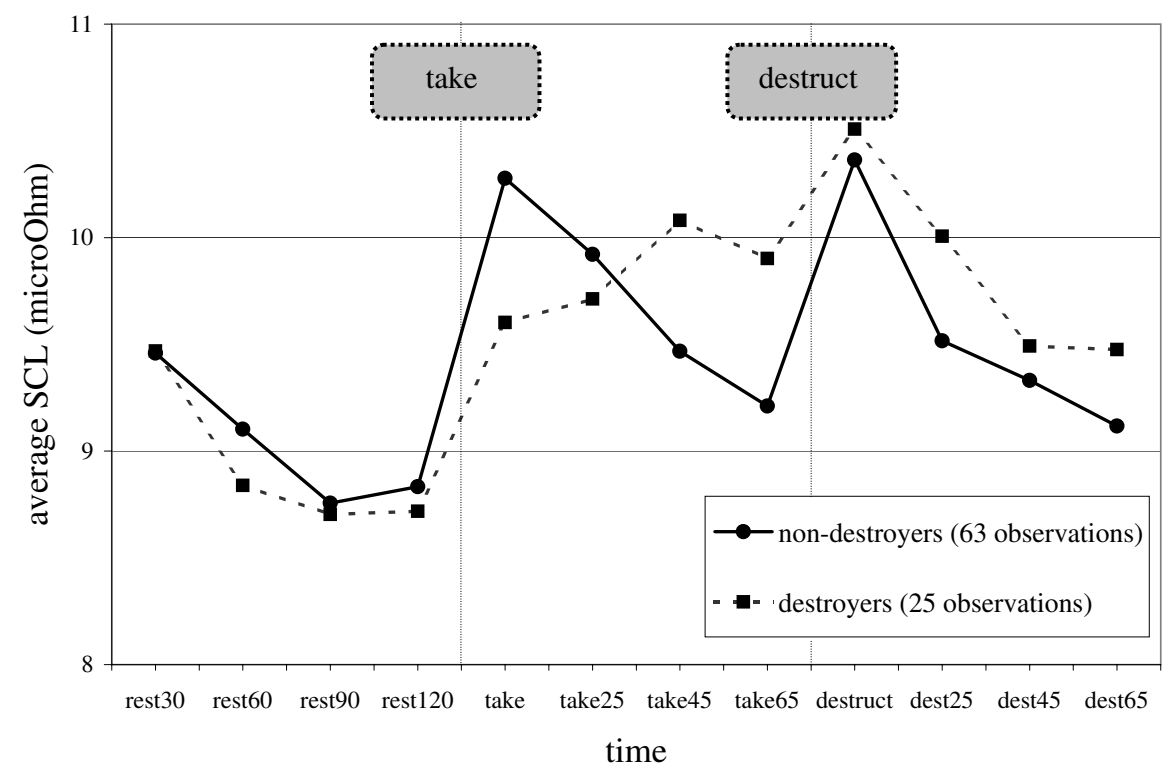

Figure 3: Timeline of SCL, for all responders connected to electrodes for measuring SC split over destruction decision.

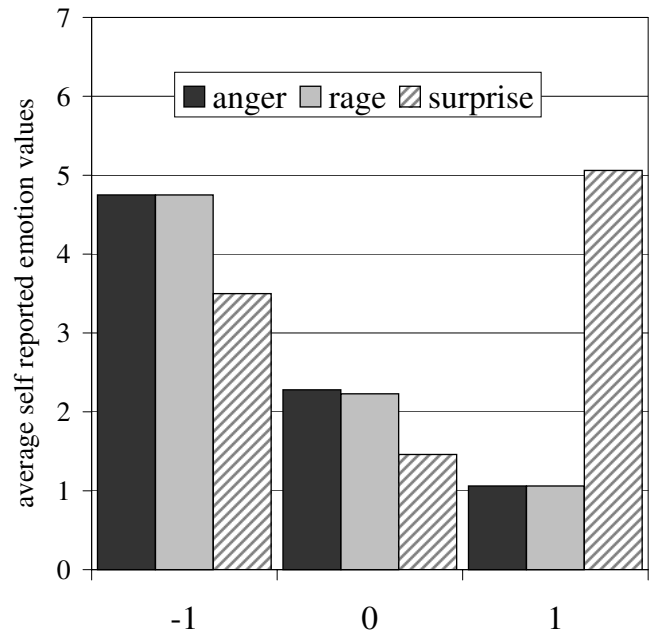

(a)

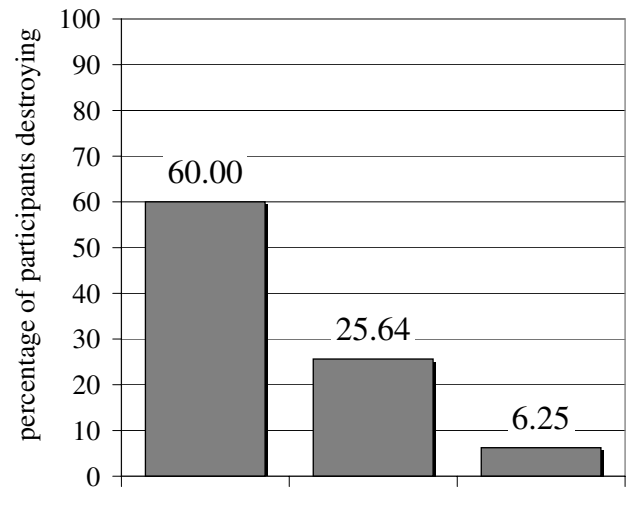

$-1$
1

(b)

Figure 4: Influence of players' expectations. Responders' expectations were coded as -1 if they expected a lower take rate, +1 if they expected a higher take rate, and 0 if they faced the take rate they expected. (a) Average self-reported emotion values dependent on expectations. (b) Percentage of players destroying something, dependent on expectations. 